\title{
Endoscopic mucosal resection using a cap: Techniques for use and preventing perforation
}

\author{
Haruhiro Inoue $\mathrm{MD}^{1}$, Tatsuyuki Kawano $\mathrm{MD}^{1}$, Masao Tani $\mathrm{MD}^{1}$, Kimiya Takeshita $\mathrm{MD}^{2}$, Takehisa Iwai $\mathrm{MD}^{1}$
}

\begin{abstract}
H Inoue, T Kawano, M Tani, K Takeshita, T Iwai. Endoscopic mucosal resection using a cap: Techniques for use and preventing perforation. Can J Gastroenterol 1999;13(6):477480. Endoscopic mucosal resection (EMR) is one of several local treatments that provide a specimen for histopathological analysis. The authors developed a technique of EMR using a transparent plastic cap (EMRC) in 1992. By using the EMRC procedure, any part of the gastrointestinal tract mucosa can be easily accessed. The technical details of EMRC are described. The authors have performed EMR in 380 cases of gastrointestinal lesions. The most serious complication may be perforation. Two perforations (one in the esophagus and one in the colon) have occurred. By evaluating recorded videotapes, it was determined that the lack of submucosal saline injection was the major cause. Therefore, large volume injection, which creates a large bleb and potentially reduces the risk of perforation, is recommended. Furthermore, target mucosa should be strangulated at the middle part of the created bleb (never strangulated at the base). Particularly in the colon, injecting a sufficient volume of saline and controlling the power of suction are extremely important, because the cap on the colonoscope is relatively large in size.
\end{abstract}

Key Words: Endoscopic mucosal resection; Endoscopy; Mucosal cancer

\section{Résection de la muqueuse à l'aide d'un endoscope à capuchon : technique d'utilisation et prévention de la perforation}

\begin{abstract}
RÉSUMÉ : La résection endoscopique de la muqueuse (REM) est un traitement local qui permet de prélever un spécimen pour analyse histopathologique. En 1992, les auteurs ont mis au point une technique de REM qui repose sur l'utilisation d'un endoscope muni d'un capuchon de plastique transparent. Avec cette technique, que l'on décrit dans le présent article, il est facile d'accéder à tout le tractus digestif;. Les auteurs ont effectué une REM sur 380 lésions gastro-intestinales. La complication la plus grave est probablement la perforation. Deux perforations (l'une dans l'œsophage, l'autre dans le côlon) se sont produites. En examinant les enregistrements sur vidéocassette, on a déterminé que l'absence d'injection saline sur la muqueuse pourrait en être la principale cause. C'est pourquoi on recommande l'injection de forts volumes pour créer une grosse bulle et réduire potentiellement le risque de perforation. De plus, la muqueuse ciblée doit être étranglée à la partie médiane de la bulle créée (et jamais à sa base). Particulièrement dans le cas du côlon, l'injection d'un volume de solution saline suffisant et le contrôle de la puissance de succion sont d'une extrême importance étant donné que le capuchon du colonoscope est relativement volumineux.
\end{abstract}

$\mathrm{R}$ ecently, various local treatments, such as laser ablation, argon-plasma coagulation, irradiation, heat probe, etc, have been advocated to treat mucosal cancer in the gastrointestinal tract, but endoscopic mucosal resection (EMR) is the only technique to acquire the resected specimen, which contributes to histopathological analysis. Definitive therapeutic strategies can now be based on histological results.

\section{PRINCIPLE}

The gastrointestinal tract has two major components - mucosal and muscle layers. Mucosa grows from the internal germ layer, and the muscle layer is derived from the middle germ layer of viviparity. These two components are attached to each other by loose connective tissue of the submucosa and can be easily separated by external force. That is why the mucosa can be resected from inside the cavity, leaving the muscle layer intact.

The gastrointestinal wall has about $4 \mathrm{~mm}$ of full thickness; therefore, special care is required to avoid muscle involvement during strangulation of mucosa. Injecting saline solution into the submucosal layer is the simplest way to avoid muscle involvement. Injected saline works as a cushion between the mucosa and the submucosa, and this cushion potentially reduces the risk of perforation. Submucosal

\footnotetext{
${ }^{1}$ First Department of Surgery and ${ }^{2}$ Department of Endoscopy, Tokyo Medical and Dental University, Tokyo, Japan

Correspondence and reprints: Dr Haruhiro Inoue, First Department of Surgery, Tokyo Medical and Dental University, 1-5-45 Yushima, Bunkyo, Tokyo 113-8519, Japan. Telephone 81-3-5803-5255, fax 81-3-3817-4126, e-mail hiro.inoue.srg1@med.tmd.ac.jp
} 
TABLE 1

Classification of mucosal resection techniques

\begin{tabular}{|c|c|}
\hline 'Without-suction' techniques & 'With-suction' techniques \\
\hline $\begin{array}{l}\text { 'Strip-off biopsy', endoscopic } \\
\text { resection using hypertonic } \\
\text { saline with adrenalin } \\
\text { (injection and snaring) (3) }\end{array}$ & $\begin{array}{l}\text { Endoscopic esophageal mucosal } \\
\text { resection-tube method }{ }^{*} \\
\text { (injection and snaring using an } \\
\text { overtube) (9) }\end{array}$ \\
\hline $\begin{array}{l}\text { 'Double-snare polypectomy' } \\
\text { (grasping and snaring) (3) }\end{array}$ & \multirow{2}{*}{$\begin{array}{l}\text { Endoscopic esophageal mucosal } \\
\text { resection under negative } \\
\text { pressure control* (injection and } \\
\text { snaring using an overtube) (10) }\end{array}$} \\
\hline $\begin{array}{l}\text { Combination of strip-off biopsy } \\
\text { and double-snare }\end{array}$ & \\
\hline polypectomy (8) & Endoscopic mucosal resection using \\
\hline $\begin{array}{l}\text { Endoscopic esophageal mucosal } \\
\text { resection using a transparent }\end{array}$ & $\begin{array}{l}\text { a cap (injection and snaring } \\
\text { using a cap) (5-7) }\end{array}$ \\
\hline $\begin{array}{l}\text { tube* (grasping and snaring }^{*} \\
\text { using an overtube) (4) }\end{array}$ & $\begin{array}{l}\text { 'Simple-suction technique'* } \\
\quad \text { (snaring using a stiff snare) (11) }\end{array}$ \\
\hline
\end{tabular}

*Only available for use in the esophagus

saline injection lifts the mucosa readily in the gastrointestinal tract. After sufficient volume injection, the mucosa, including the target lesion, can be safely captured and strangulated by the snare wire, and then easily resected by electrocautery.

\section{HISTORY AND CLASSIFICATION OF EMR TECHNIQUES}

In 1955, in the era of the rigid scope, Rosenberg (1) reported the importance of submucosal saline injection during polypectomy of rectal and sigmoidal polyps. In 1973, Deyhle et al (2) highlighted the usefulness of submucosal saline injection for the treatment of sessile colonic polyps using a flexible endoscope. Then in 1989, Takemoto et al (3) advocated the concept of mucosal resection for flat and depressed-type mucosal cancer in the stomach.

In 1990, we reported our first experience with mucosal resection in the esophagus by using a newly designed transparent tube (4), and in 1992, we developed a technique of EMR using a hood-type distal attachment (cap) (EMRC), which makes the EMR procedure simple and allows easy access to any part of the gastrointestinal tract lesions (5-7). Some other mucosal resection techniques have been advocated (8-11). These are classified in Table 1.

Our technique for the EMRC procedure (EMR using a cap-fitted endoscope, where the 'cap', made from transparent plastic, is a distal attachment on forward-view endoscope) is as follows.

1. In preparation for the EMRC procedure, a cap is attached to the tip of the forward-view endoscope and is fixed tightly with adhesive tape. A cap is commercially available in Europe and Asia (distal attachment, Olympus, Tokyo, Japan). The cap is pending approval by the United States Food and Drug Administration in the United States, and by Health Canada in Canada.

2. The mucosal surface that surrounds the margin of the lesion should be carefully marked by the tip of the snare wire. Markings are positioned $2 \mathrm{~mm}$ apart from the lesion margin.

3. Five hundred thousand times diluted adrenalin saline solution $(0.1 \%$ adrenalin solution $0.2 \mathrm{~mL}$ plus normal saline $100 \mathrm{~mL}$ ) is injected into the submucosa with an injection needle. The total volume of injected saline depends on the size of the lesion, but it is necessary to inject enough saline to lift the whole lesion up. Usually more than $20 \mathrm{~mL}$ is injected.

4. The snare wire is prelooped along the rim of the EMRC cap with a specially designed small-diameter snare SD-7P (2 mm outer diameter) (Olympus). At first, moderate suction is applied to the mucosa to seal the outlet of the cap (Figure 1, top), then, the snare wire that passes through the instrumental channel of the endoscope is opened (Figure 1, middle). The opened snare wire is fixed along the rim of the cap, and the outer sheath of the snare sticks up into the rim of the cap (Figure 1, bottom). This completes the 'prelooping' of the snare wire.

5. To approach the target mucosa (Figure 2, top), the target mucosa, including the lesion, is fully sucked inside the cap and is strangulated by the snare wire (Figure 2, middle). At this moment, the strangulated mucosa looks like a snared polypoid lesion (Figure 2, bottom).

6. The pseudopolyp of the strangulated mucosa is cut by electrocautery. The resected specimen can be easily taken out by keeping it inside the cap without using any grasping forceps.

7. If additional resection is necessary, all the steps of the procedure, including saline injection, should be repeated.

\section{CLINICAL RESULTS}

In the authors' institute, more than 175 cases of early-stage esophageal cancer received mucosal resection, mainly by two techniques $(5,10)$. Seventy-two per cent of all cases were absolute indications for mucosal resection according to the authors' criteria. The rest were relatively indicated cases because they were at poor risk for surgery or refused to undergo surgery. In absolutely indicated cases, no local or distant metastasis was identified during the follow-up period. The five-year survival rate was $95 \%$, including other causes of death. All who died during the five-year follow-up period suffered from other fatal diseases such as myocardial infarction, liver cirrhosis and stroke. One patient in the early series encountered perforation of the esophagus, a major complication. Perforation occurred during the second cauterization. By conservative treatment such as intravenous hyperalimentation and antibiotics administration, the patient recovered and had no concomitant problems. Eight years later, she is living healthy with no accident-related complaints. Another patient who received near total circumferential mucosal resection developed persistent stenosis that could not be controlled by the repeated forceful balloon dilation and was 


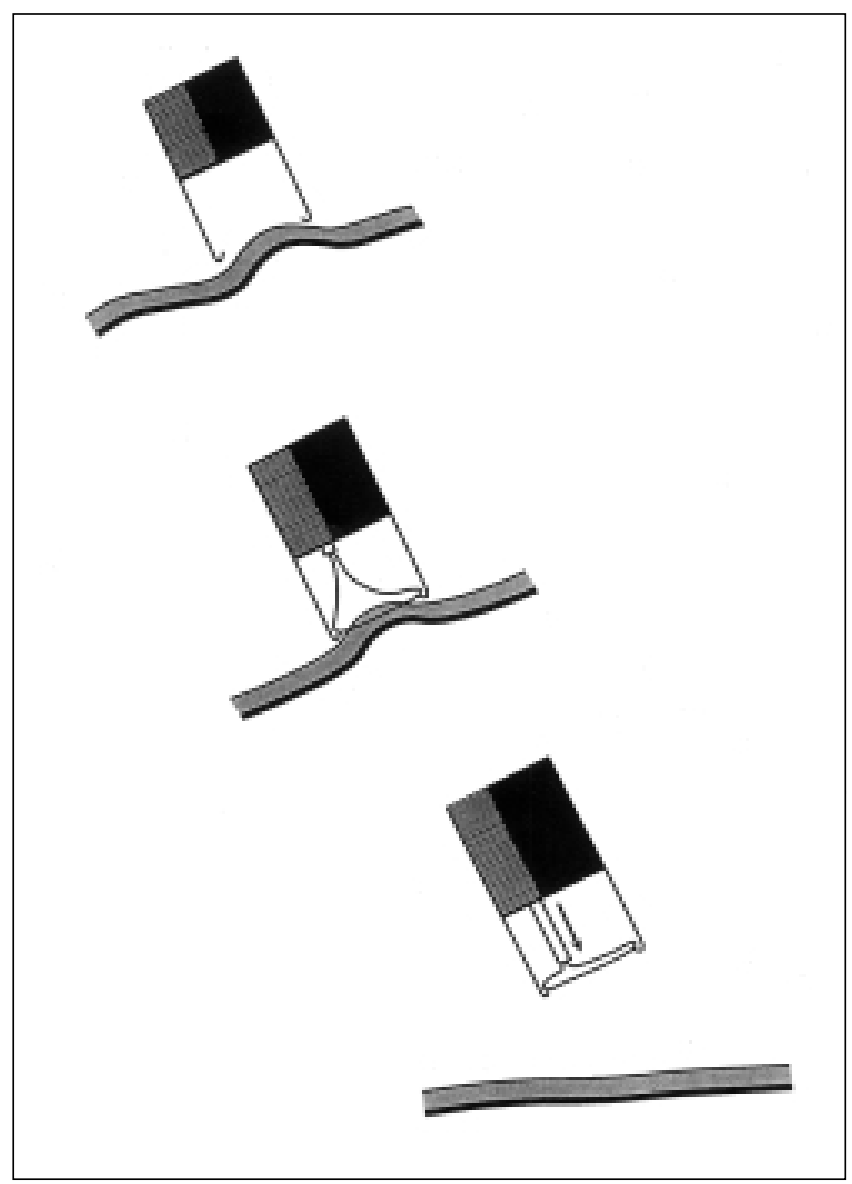

Figure 1) Schema of the procedure for prelooping during endoscopic mucosal resection using a cap-fitted endoscope (EMRC). Top The normal mucosa is suctioned and the outlet of the EMRC cap sealed. Middle The snare wire is opened and moves along the rim of the cap. Bottom A 'prelooping' condition is created. The outer sheath of the snare pushes up to the distal end of the cap

finally treated by surgical esophagectomy. Five years later, he is also living in good condition.

\section{MECHANISM OF PERFORATION}

To evaluate the mechanism of muscle involvement, surgically resected human esophagus, stomach and colon were included in the study. Specimens were stretched on a rubber board and then sunk into a basin filled with de-aerated water. The EMRC procedure is performed on the fixated specimens, and the whole process is recorded on videotape recorder by ultrasonography. Without saline injection, the muscle layer beneath the surface mucosa is also drawn into the cap together with mucosa, which results in a potential risk of muscle involvement at the closure of the snare loop. Small-volume saline creates the small bleb (Figure 3A). Full suction for a small bleb still carries a risk of muscle involvement (Figure 3B,C). Extra large volume saline injection creates a large bleb (Figure 3D). This large cushion mechanically prevents muscle involvement (Figure 3E,F). In other words, the mucosa should not be snared at the base of the lifted mucosa (Figure 3B); it should always be snared at the middle part of the lifted mucosa (Figure 3E). This caution is

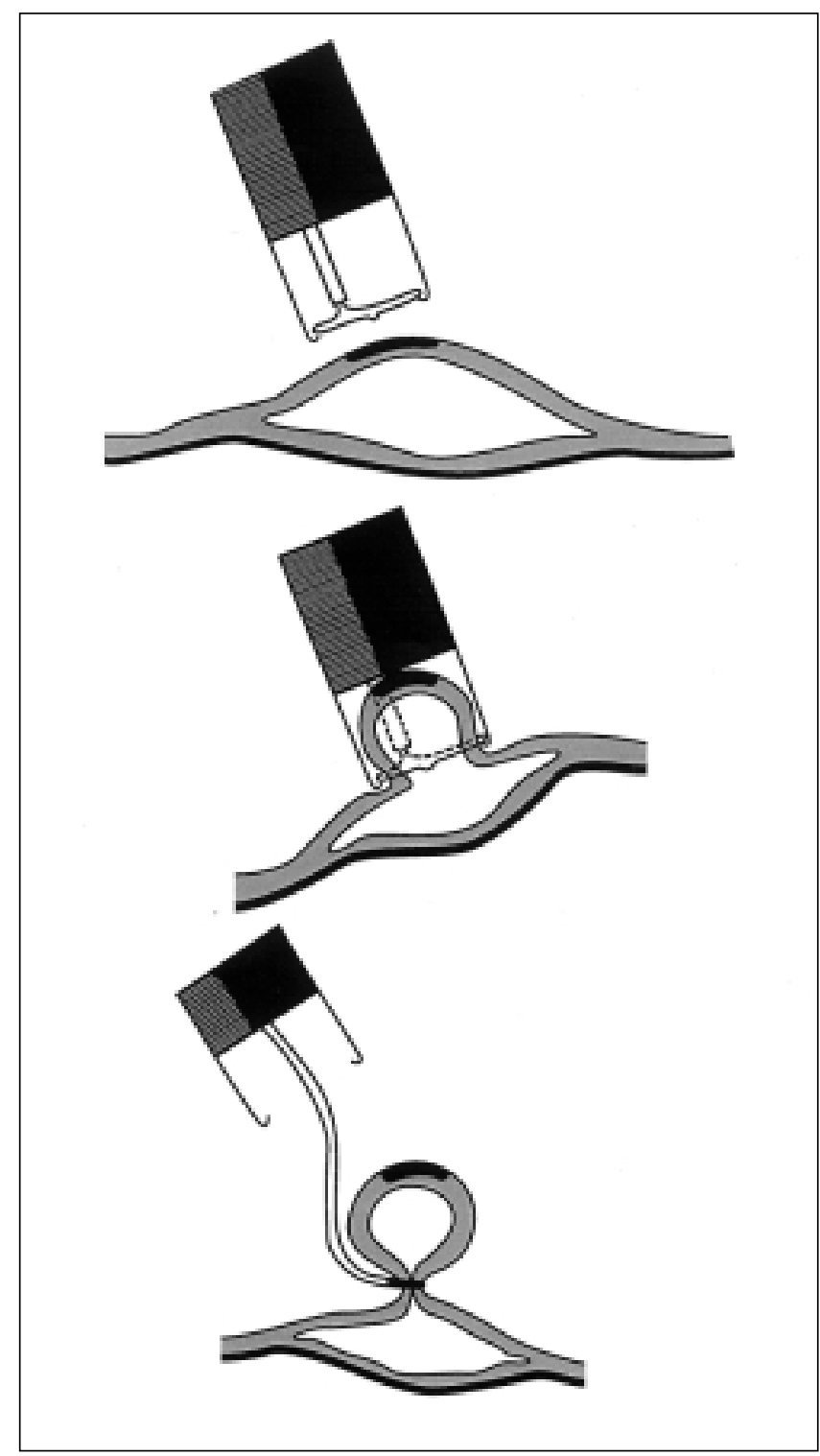

Figure 2) Schema of the procedure for endoscopic mucosal resection using a cap-fitted endoscope. Top After injection, the endoscope proceeds to the lesion. Middle The target mucosa is drawn into the cap. Bottom The strangulated target mucosa

especially important in the colon, because a relatively large cap is used in colonoscopy.

The 'with-suction' techniques listed in Table 1 have a potentially higher risk of muscle involvement than the 'without-suction' techniques; therefore, injecting a large volume of saline into the submucosa is highly recommended.

\section{COMMENTS}

As mentioned above, the largest risk factor that potentially causes perforation is the lack of submucosal saline injection. To prevent perforation, large-volume saline injection is considered to be important. In the esophagus, around $20 \mathrm{~mL}$ saline causes more than half circumferential mucosal dissection, with the mucosal surface remaining about $1 \mathrm{~cm}$ apart from the muscle layer (Figure 3D-F). In the stomach, EMR 


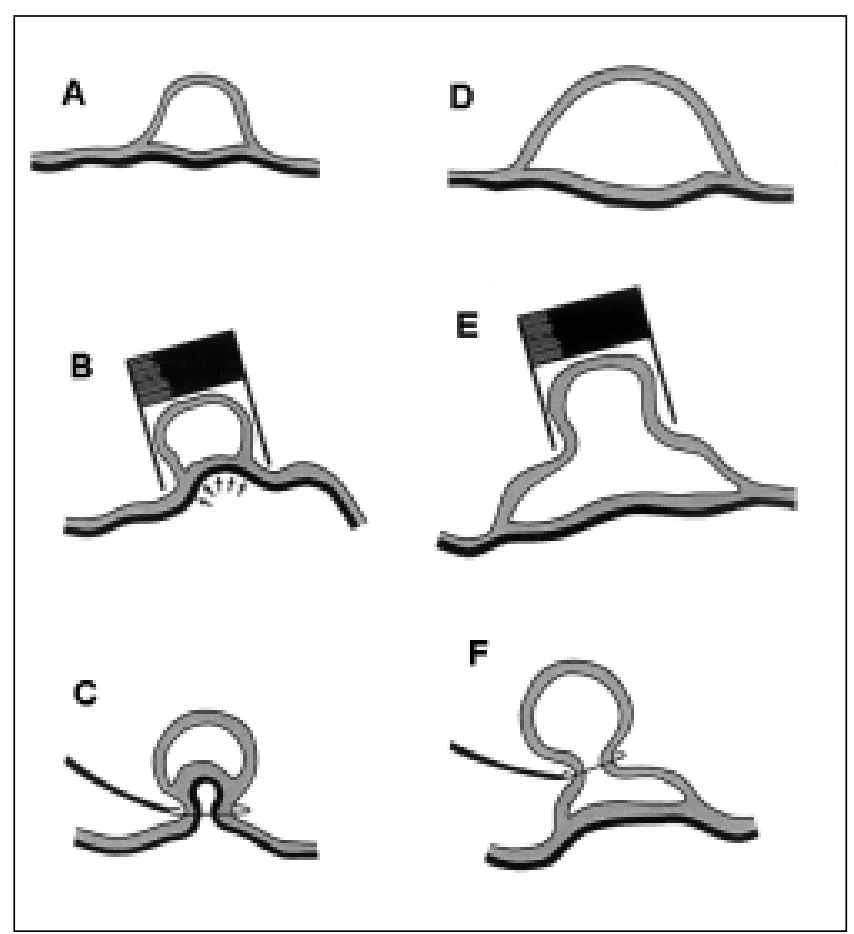

Figure 3) A Small volume injection creates a small bleb. B The target mucosa is sucked into the cap. C The snare also strangulates the muscle layer. D Large volume injection creates the large bleb. E Endoscopic mucosal resection on a large bleb causes no traction of the muscle layer. $\mathrm{F}$ The snare wire should strangulate the target mucosa at the middle part of the lifting

can be safely performed, in general, because it has a relative thick muscle layer. However, at the lessor curvature in the upper and middle thirds of the stomach, special attention is necessary to avoid muscle involvement because stretching of the mucosa is limited. Using the small capacity cap or reducing the suction power makes the procedure safer. In the colon, attention should be paid to avoid perforation, because in the colon, a relatively large sized cap is used for EMR, and the muscle layer itself is thinner than that of the other gastrointestinal tract wall. In our experience with removing a creeping tumour in the rectum, about $100 \mathrm{~mL}$ of saline was injected, and the whole lesion was safely removed with induction of the half circumferential ulceration. In this case, the post-therapeutic course was uneventful; therefore, large-volume saline injection is considered to be a safe procedure. It is not technically difficult to control the position of the needle tip into the submucosal layer. Puncturing the mucosa with a sharp angle is the most important key to avoiding transmural penetration. If saline is accurately injected into the submucosal layer, lifting or bulging of the mucosa is always observed in any part of the gastrointestinal tract. With a sufficient volume of submucosal injection, EMR can always be performed quite safely.

In almost all EMR cases, the quality of life after resection is maintained $(12,13)$, so we believe that early detection of cancerous lesions and the treatment of them by EMR are ideal goals of cancer treatment.

\section{REFERENCES}

1. Rosenberg N. Submucosal saline wheal as safety factor in fulguration of rectal and sigmoidal polypi. Arch Surg 1955;70:120-2.

2. Deyhle P, Largiader F, Jenny S, Fumagalli I. A method of endoscopic electroresection of sessile colonic polyps. Endoscopy 1973;5:38-40.

3. Takemoto T, Tada M, Yanai H, Karita M, Okita K. Significance of strip biopsy with particular references to endoscopic "mucosectomy." Digest Endosc 1989;1:4-9.

4. Inoue H, Endo M. Endoscopic esophageal mucosal resection using a transparent tube. Surg Endosc 1990;4:198-201.

5. Inoue H, Takeshita K, Hori H, Muraoka Y, Yoneshima H, Endo M. Endoscopic mucosal resection with a cap-fitted panendoscope for esophagus, stomach and colon mucosal lesions. Gastrointest Endosc 1993;39:58-62.

6. Tada M, Inoue $\mathrm{H}$. Colonic mucosal resection using a transparent cap-fitted endoscope. Gastrointest Endosc 1996;44:63-5.

7. Izumi Y, Teramoto K, Ohshima M, Shin S, Yamamura A, Matsumoto M. Endoscopic resection of duodenal ampulla with a transparent plastic cap. Surgery 1998;123:109-10.

8. Monma K, Sakaki N, Yoshida M. [Endoscopic mucosectomy for precise evaluation and treatment of esophageal intraepithelial cancer]. Endoscopia Digestiva 1990;2:501-6.

9. Makuuchi H, Machimura T, Sugihara T, et al. [Endoscopic diagnosis and treatment of mucosal cancer of the esophagus]. Endoscopia Digestiva 1990;2:447-52.

10. Kawano T, Miyake S, Yasuno M, et al. A new technique for endoscopic esophageal mucosectomy using a transparent overtube with intraluminal negative pressure. Dig Endosc 1991;3:159-67.

11. Soehendra N, Binmoeller KF, Bohnacker S. Endoscopic snare mucosectomy in the esophagus without any additional equipment: a simple technique for resection of flat early cancer. Endoscopy 1997;29:380-3.

12. Takeshita K, Tani M, Inoue H, et al. Endoscopic treatment of early oesophageal or gastric cancer. Gut 1997;40:123-7.

13. Inoue $\mathrm{H}$. Endoscopic mucosal resection for esophageal and gastric mucosal cancers. Can J Gastroenterol 1998;12:355-9. 


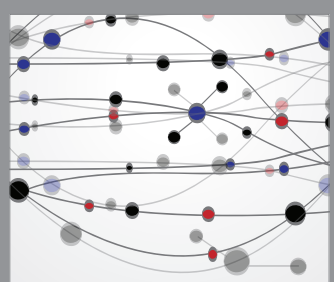

The Scientific World Journal
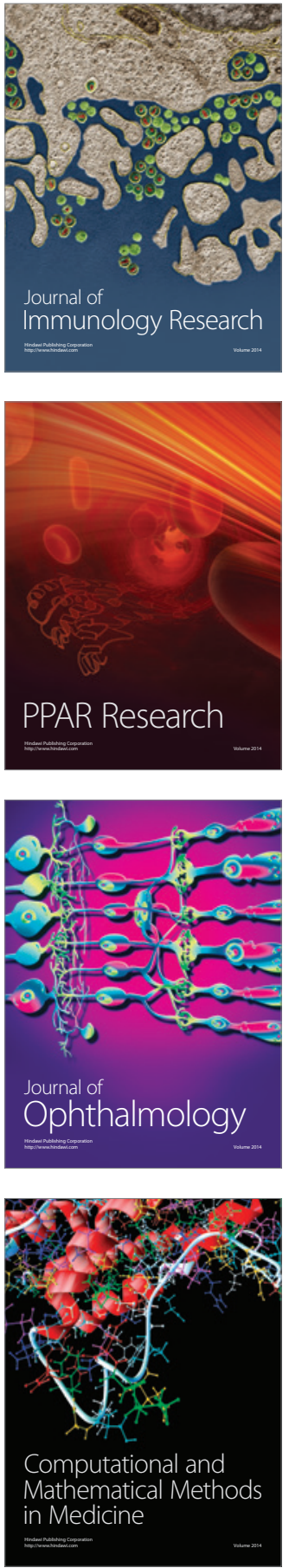

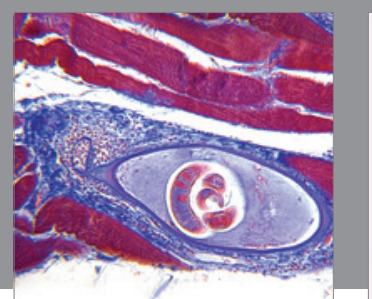

Gastroenterology Research and Practice

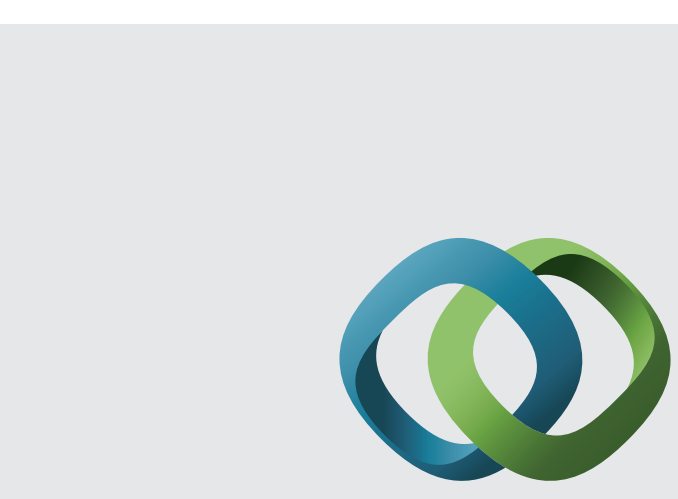

\section{Hindawi}

Submit your manuscripts at

http://www.hindawi.com
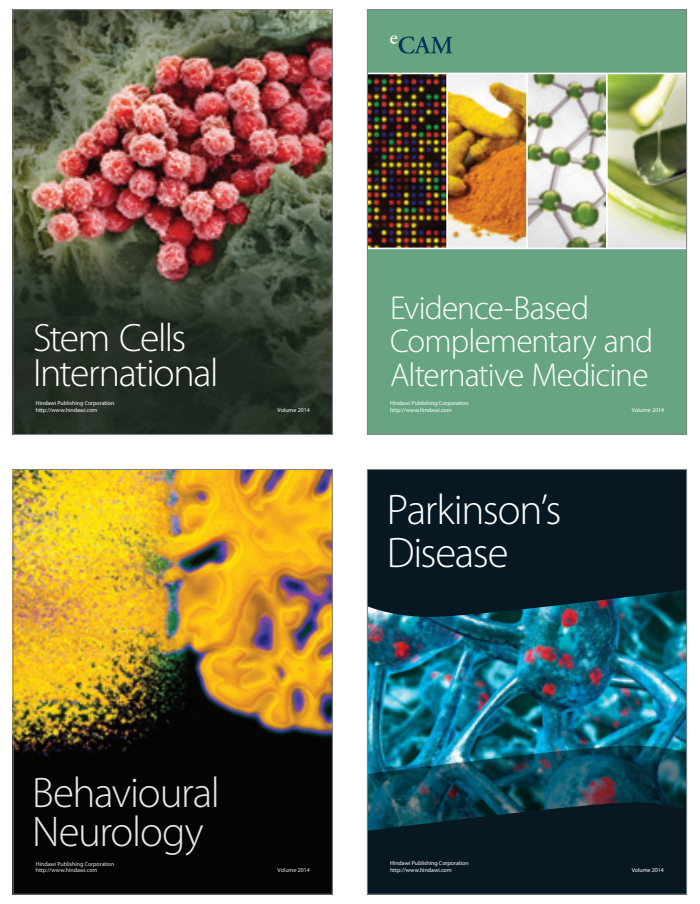
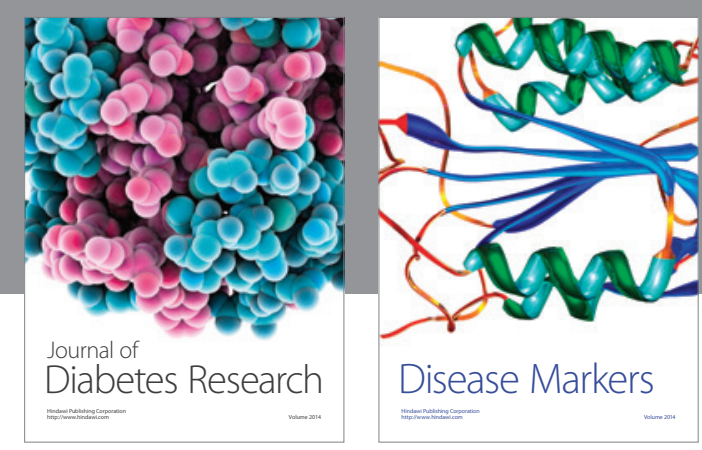

Disease Markers
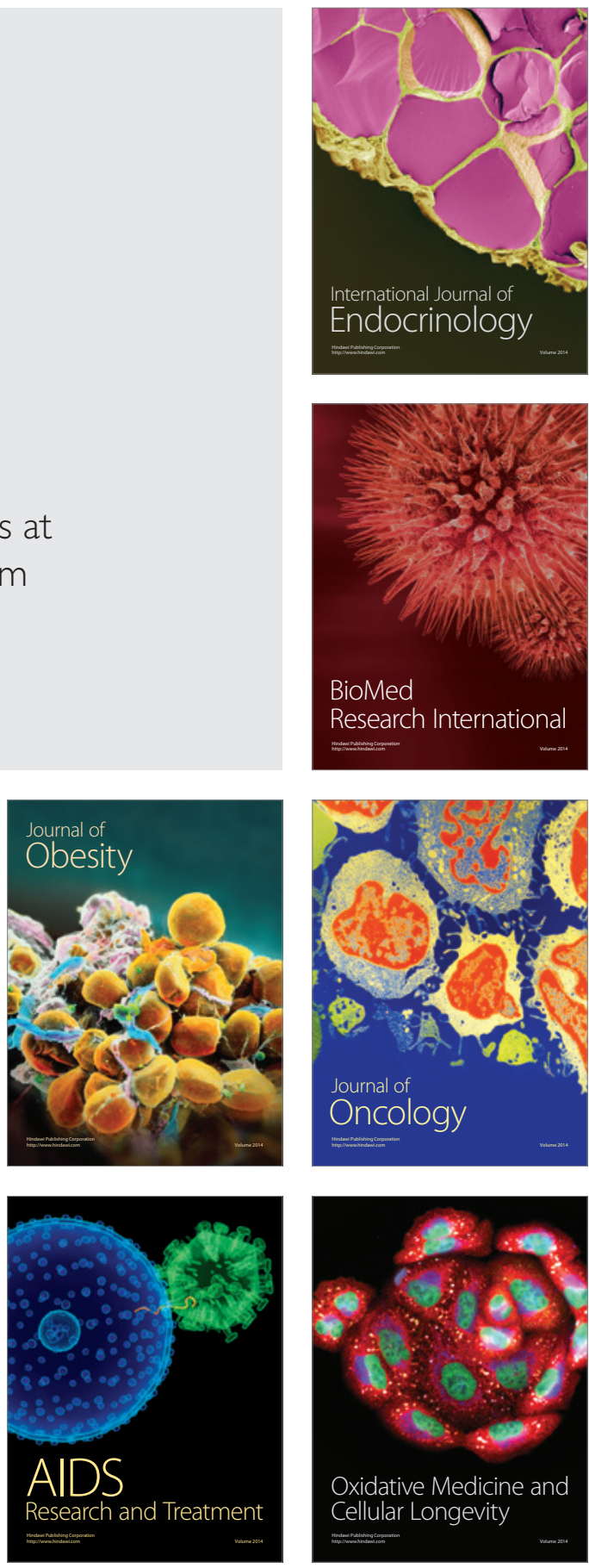